\title{
Unilateral Retinoblastoma
}

National Cancer Institute

\section{Source}

National Cancer Institute. Unilateral Retinoblastoma. NCI Thesaurus. Code C8714.

A retinoblastoma that only involves a single eye. 